\title{
ESTADO E EDUCAÇÃO DO CAMPO: A INFLUÊNCIA DOS ORGANISMOS INTERNACIONAIS NA ELABORAÇÃO DE POLÍTICAS PÚBLICAS EDUCACIONAIS PARA O CAMPO BRASILEIRO
}

\author{
SÁvia Bona Soares \\ Secretaria de Educação do Distrito Federal (SEE-DF), Brasília, Distrito \\ Federal, Brasil
}

\begin{abstract}
Resumo: O marco do surgimento da Educação do Campo ocorre em 1997, em um encontro sediado em Luziânia - GO, organizado primordialmente pelo Conselho Nacional de Bispos do Brasil (CNBB), pelo Movimento dos Trabalhadores Rurais Sem Terra (MST), pela Universidade de Brasília (UnB) e pelas organizações internacionais UNESCO e UNICEF. Em nosso estudo, temos como objetivo analisar as contradições da institucionalização da Educação do Campo. Para isso, buscamos refletir acerca do Programa Nacional de Educação na Reforma Agrária. Objetivamos também mostrar a influência do Banco Mundial nos projetos educacionais e investigar seu projeto para o campo e a educação no campo brasileiro. Para isso, utilizamos pesquisa bibliográfica e documental, analisando relatórios do Banco Mundial, bem como dados fornecidos pelo Ministério da Educação.

Palavras-chave: Banco Mundial. Educação do Campo. PRONERA. UNESCO.
\end{abstract}

1 INTRODUÇÃO

O movimento Educação do Campo tem sua origem em 1997, durante - $1^{\circ}$ Encontro Nacional de Educadores e Educadoras da Reforma Agrária (I ENERA). Esse primeiro encontro conta com a presença do Movimento dos 
Trabalhadores Rurais Sem Terra (MST), da Universidade de Brasília (UnB), do Fundo Nacional das Nações Unidas para a Infância (UNICEF), da Organização das Nações Unidas para a Educação, Ciência e Cultura (UNESCO) e da Conferência Nacional dos Bispos do Brasil (CNBB). Segundo Freitas (2007), esse encontro conseguiu reunir mais de 700 professores de assentamentos rurais e "de instituições universitárias que vinham atuando em projetos de educação em assentamentos" (p.19). O I ENERA teve como resolução a realização de um grande encontro nacional, que seria articulado a partir de conferências estaduais.

Em 1998, foi realizada a I Conferência Nacional por uma Educação Básica do Campo, que contou com a presença das entidades presentes no ENERA (CNBB, UNESCO, MST, UNICEF, UNESCO e UnB) e também com outros movimentos sociais, as EFAs (Escolas Famílias), organizações governamentais (MEC) e não governamentais. A partir dessa conferência, a Educação do Campo foi "batizada" com esse nome. Segundo informações do site do MST, a conferência buscava impulsionar uma educação "[...] que garantisse o direito à educação às populações do campo e que as experiências político-pedagógicas acumuladas por estes sujeitos fossem reconhecidas e legitimadas pelo sistema público nas suas esferas correspondentes"1. Segundo Santos (2013), o resultado da conferência foi a instituição de uma comissão dos movimentos sociais para atuarem junto ao MEC na discussão da Educação do Campo. Posteriormente, foram realizadas mais duas conferências, uma em 1998 e outra em 2004.

Esse encontro ocorre em uma conjuntura interessante. Podemos observar que, de um lado, tem-se uma percepção da necessidade de reivindicar uma ampliação da educação para os trabalhadores e, ao mesmo tempo, que esta busque romper com um modelo de educação apenas instrumentalista, defendido pelos movimentos sociais do campo. Em contrapartida, vemos cada vez mais uma pressão externa encabeçada pelo Banco Mundial e apoiada pelos defensores do agronegócio, para que se desenvolva a educação instrumentalista no Brasil, tornando-se assim possível o desenvolvimento econômico capitalista do campo.

Em nosso estudo, temos como objetivo mostrar a influência do Banco Mundial nos projetos educacionais do Brasil e investigar seu projeto para o campo e a educação no campo brasileiro. Para isso, faremos um histórico do surgimento do Banco Mundial, bem como sua ligação com a UNESCO, e refletiremos acerca dos relatórios do banco que analisam e sugerem políticas para o Brasil. Além disso, iremos analisar o impacto de tais diretrizes na construção dos programas educacionais do campo e faremos uma reflexão 
acerca do Programa Nacional de Educação na Reforma Agrária como uma das principais políticas públicas da Educação do Campo.

\section{O SURGIMENTO do BANCO Mundial E SUA PROPOSTA ORgANIZATIVA}

O que chamamos de "Banco Mundial" consiste em um grupo que divide-se em sete organizações que apresentam diferentes funções. São elas: o Banco Internacional para a Reconstrução e o Desenvolvimento (BIRD), a Associação Internacional de Desenvolvimento (AID), a Corporação Financeira Internacional (CFI), a Agência Multilateral de Garantias e Investimentos (AMGI), o Instituto do Banco Mundial (IBM), o Painel de Inspeção e o Centro Internacional para Conciliação de Divergências em Investimentos (CICDI). De acordo com Pereira (2009), em geral, quando encontramos escritos sobre o Banco Mundial, estes estão se referindo ao BIRD e/ou à AID. Os países com maior poder de voto no banco são os Estados Unidos, o Japão, a Alemanha, o Reino Unido e a França, respectivamente, sendo que os Estados Unidos mantêm uma posição de privilégio em relação aos outros quatro, tendo poder de voto superior à somatória dos outros três países mais influentes (Japão, Alemanha e Reino Unido).

Nascido em 1944, junto com o FMI, o BIRD foi fruto de um projeto que visava consolidar a hegemonia mundial norte-americana e não, como acreditam alguns, desenvolver humanitariamente as nações amigas no pósguerra. Almejavam minar de uma vez por todas a preferência inglesa no mundo capitalista, além de tentar configurar-se como hegemonia econômica e ideológica, tentando suprimir o poder da União Soviética. Para isso, visavam à expansão dos mercados e ao estabelecimento de barreiras à expansão do comunismo. Tinha-se em mente restabelecer os mercados e, principalmente, dar novamente aos empresários a possibilidade de lucros exorbitantes. $\mathrm{O}$ banco foi e ainda é um instrumento de fortalecimento do capitalismo e da liderança norte-americana no contexto mundial.

Já no primeiro dia da conferência de Bretton Woods, que fundou o BIRD e o FMI, os Estados Unidos (EUA) deixam claro suas intenções no comunicado oficial do país destinado à imprensa após o primeiro dia do encontro:

O propósito da conferência está [...] por inteiro dentro da tradição estadunidense e é completamente alheio a considerações políticas. Depois desta guerra, os Estados Unidos querem a utilização total de suas indústrias, fábricas e fazendas, emprego pleno e constante para seus cidadãos, em particular seus ex-militares, e paz e prosperidade completas. Para isso é preciso um mundo com um comércio vigoroso e este somente pode ser alcançado se 
as moedas são estáveis, se o dinheiro conserva seu valor e se as pessoas podem comprar e vender com a certeza de que o dinheiro que recebem na data do vencimento terá o valor que contrataram, e a isto se deve a primeira proposta, a do Fundo de Estabilização. Uma vez que tenhamos valores seguros e estáveis, o próximo passo será promover a reconstrução mundial, retomar o comércio normal e pôr fundos à disposição das empresas solventes, o que demandará, por sua vez, produtos estadunidenses (U.S. DEPARTMENT OF STATE, 1948, p.1148 apud PEREIRA, 2010, p. 103).

O banco, que realizava mais empréstimos para a Europa, foi direcionando seu foco para a América Latina e a África e, em 1959, houve uma modificação drástica do montante dos empréstimos. As guerras de libertação nacional nos países africanos e a crescente simpatia a governos de esquerda na América Latina, mais a revolução em Cuba, fizeram com que os EUA, membro majoritário do Banco Mundial, tivessem um enorme receio do avanço do comunismo nessas regiões. Sendo assim, resolveram intensificar os empréstimos e as intervenções nos países africanos e latino-americanos.

A intervenção estadunidense na América Latina aparece, através do Banco Mundial, travestida de uma ajuda humanitária com um "estímulo democrático", a fim de estimular os países a recomporem suas economias e assim fazer uma distribuição da riqueza. Segundo Pereira (2009), os empréstimos do BIRD voltados para as áreas sociais tais como saúde, saneamento e educação só começam a ter importância a partir das décadas de 1960 e 70. De acordo com o autor, apesar da retórica, "o BIRD jamais apoiou ou financiou qualquer iniciativa governamental voltada à redistribuição de riqueza e, especialmente à democratização da estrutura agrária" (PEREIRA, 2009, p. 85, grifo nosso).

\section{Diretrizes do Banco Mundial para o campo e a educação}

Uma área que ganhou notável atenção do BIRD foi o meio rural. Sentia-se uma necessidade de expandir e modernizar o campo nos países "pobres" e "emergentes" para que estes virassem mercado consumidor dos produtos norte-americanos. Nas décadas de 1950, 1960 e 1970, a Fundação Rockefeller ${ }^{2}$, junto do governo americano, consegue produzir sementes híbridas de trigo e posteriormente de milho e arroz, com alta produtividade, mas que dependiam de certas condições ideais para funcionarem, tais como irrigação adequada, uso de pesticidas, fertilizantes químicos, máquinas agrícolas, etc. A fim de difundir essas inovadoras sementes e os fertilizantes, houve uma pressão das empresas que os produziam para que o Banco Mundial e a United States Agent of International Development (USAID) 
financiassem os países da periferia do capitalismo para que eles pudessem adquirir o material tecnológico necessário para o manejo de seus produtos. Esse processo ficou conhecido mundialmente como Revolução Verde, processo que foi disseminado também no campo brasileiro. Segundo Pereira (2009), houve outro fator que incentivou o banco a investir na agricultura, que seria "a aceitação da tese [...] segundo a qual os agricultores 'tradicionais' seriam receptivos a incentivos econômicos e predispostos à otimização da produção conforme o estilo ocidental" (p. 107).

Na área educacional, nota-se que, de início, o Banco Mundial não tinha um foco tão grande na educação, encontrando, inclusive, muita resistência ao se realizarem propostas de financiamento para áreas sociais como um todo. Entretanto, a partir das décadas de 1960 e 1970, o orçamento voltado para a área da educação subiu significativamente, passando de US\$ 62 milhões, de 1968-70, para US\$ 194 milhões, entre 1971-73. Esse fato está intimamente ligado com o processo da chamada Revolução Verde (ou também chamada de Modernização Conservadora), como podemos perceber pelo enfoque inicial das políticas educacionais que foram inicialmente voltadas ao que eles chamaram de "ensino produtivo", que seria o ensino agrícola e o extensionista. Já a partir de 1968, houve uma concentração da atenção no ensino fundamental.

A partir desse ano, iniciou-se um alinhamento intenso entre o Ministério da Educação brasileiro e o Banco Mundial. Segundo Júnior e Maués (2014), esse alinhamento era tão significativo que os principais responsáveis pelas políticas educacionais do Brasil já haviam feito parte da equipe de agências que compõem o BIRD. Segundo os pesquisadores, Paulo Renato Souza (ministro da Educação durante os dois mandatos de Fernando Henrique Cardoso), Guiomar Nano de Mello (membro do Conselho Nacional de Educação a partir de 1997 até o fim do mandato de FHC) e Cláudia Costin (ex-ministra da Administração) eram alguns exemplos.

Uma questão clara no que se refere à educação proposta pelo Banco Mundial aos países da periferia do capitalismo é a centralidade da importância no ensino fundamental. Segundo Leher (2010), para o Banco Mundial, os países da periferia do capitalismo deveriam investir em educação básica fundamental para oferecer mão de obra para o mercado com um mínimo de escolaridade. Não haveria necessidade, nem razão, de um investimento grande em ensino superior, pois os países "subdesenvolvidos" não trariam grandes inovações capazes de competir com as inovações técnicas dos países"desenvolvidos". 
Além da importância de qualificar mão de obra para o mercado, a importância de investir em educação fundamental estaria também em uma disputa ideológica, na qual um amplo acesso da população ao ensino fundamental aumentaria, assim, "a coesão da sociedade e evitar[ia] protestos e descontentamento social" (WORLD BANK, 1999a, p. 51). Por outro lado, segundo a teoria defendida pelo BIRD, oferecendo a oportunidade de educação fundamental a todos os seus indivíduos, os Estados estariam oferecendo oportunidades de "crescimento econômico individual" a todos, se desresponsabilizando pelas desigualdades e pela miséria de alguns (JÚNIOR; MAUÉS, 2014).

Nessa lógica, em 1990, após uma conferência na Tailândia, a Conferência de Jomtien, o Banco Mundial uniu-se à Organização das Nações Unidas para a Educação (UNESCO), no programa "Educação para Todos", que tinha como objetivo promover a universalização da Educação Básica. A Conferência de Jomtien contou com 155 países e dois principais financiadores, o Banco Mundial e a ONU. Para Rabelo e Jimenez (2009), a conferência de Jomtiem foi um marco internacional da afirmação da educação como uma possibilidade de reprodução do paradigma neoliberal, trazendo a perspectiva da educação como meio para o alívio da pobreza e também de ampliação do chamado "capital humano", a força de trabalho.

Escolarizar todos os homens era condição para converter os servos em cidadão, era condição para que esses cidadãos participassem do processo político, e, participando do processo político, eles consolidariam a ordem democrática, democracia burguesa, é obvio, mas o papel político da escola estava aí muito claro. A escola era proposta como condição para a consolidação da ordem democrática (SAVIANI, 2003, p. 40).

Apesar de a Conferência de Jomtien não ter contado, oficialmente, com nenhum membro do governo brasileiro, o Brasil, por influência do Banco Mundial, acatou as diretrizes do programa "Educação para Todos" e determinou a criação da primeira Lei de Diretrizes e Bases da Educação (LDB) em 1996, que seguia as orientações da conferência, e indicou que o Plano Nacional de Educação fosse elaborado com base na Declaração Mundial de Educação Para Todos (RABELO; JIMENEZ, 2009).

A Declaração Mundial de Educação para Todos, apesar de ser um documento sucinto e que não traz grandes reflexões sobre a temática da educação, apresenta de maneira sutil algumas das indicações e preocupações dos signatários, comandados pela ONU e pelo Banco Mundial, em relação à educação. Segundo o documento, a educação deve servir para a redução das desigualdades e, para isso, há de se dar uma maior atenção ao que eles 
denominam de grupos excluídos: os pobres, a população das periferias urbanas e das zonas rurais, entre outros (UNESCO, 1998).

Em 1994, outro importante fato ajuda a modelar as ações do governo brasileiro para a educação. Nesse ano, o Banco Mundial lançou um relatório chamado "Brazil: the management of agriculture, rural development and natural resources".

O Banco Mundial recentemente realizou um exame em nível mundial do setor agrícola nos países para os quais empresta dinheiro. Este estudo foi motivado pelo fraco desempenho do setor agrícola em muitos países e fraco desempenho de muitos projetos agrícolas financiados pelo Banco. Esta avaliação observa que não há uma receita única para o crescimento agrícola [...]. Mas existem características comuns nas estruturas de incentivo nestas e em outras economias agrícolas de sucesso que indicam as direções estratégicas que os países menos bem-sucedidos pode lucrativamente prosseguir [...].O papel do governo deve ser limitado e focado em: [...] O financiamento, mas não necessariamente a entrega por órgãos públicos, dos bens públicos, principalmente em pesquisa e extensão agrícola, infraestrutura rural, e os serviços de educação e de saúde rurais (BANCO MUNDIAL, 1994, p.112, tradução livre).

[...] No curto prazo, políticas emergenciais extramercado, tais como a reforma agrária e a distribuição de terras de propriedade pública, podem ser justificadas. Seja qual for o período de tempo considerado, os investimentos em capital humano (educação, saúde, saneamento) serão de extrema importância, tanto em áreas rurais quanto urbanas (BANCO MUNDIAL, 1994, p.212, tradução livre).

Esse relatório foi também um marco para a reconfiguração da educação voltada para as áreas rurais. Nele, o BIRD evidenciou a necessidade de erradicar o analfabetismo no campo e capacitar trabalhadores para o trabalho na agricultura. Segundo o órgão, essas medidas seriam primordiais para a garantia do crescimento do Brasil, por se tratar de um país com grande potencial agrícola, entretanto com mão de obra ainda não capacitada para os avanços tecnológicos (BANCO MUNDIAL, 1994).

\section{A educaÇão do Campo enduanto política pública estatal: Programa Nacional de Educação na Reforma Agrária}

Um dos marcos da discussão da educação do campo se deu no I Encontro Nacional das Educadoras e Educadores da Reforma Agrária, que ocorreu em 1997, mesmo ano da criação de outro programa voltado para 
a educação no campo brasileiro, o Programa Escola Ativa (PEA) ${ }^{3}$, e contou com a presença da CNBB, da UNESCO, do MST, do UNICEF e da UnB. Ao fim do encontro, as entidades organizadoras firmaram o compromisso de iniciar uma luta para sensibilizar a sociedade e o governo acerca da importância de se criar políticas públicas que tenham como foco a educação da população do campo. Para tal, foi formada a Articulação Nacional Por uma Educação do Campo, que, pouco tempo após sua criação, conseguiu que fosse elaborado, em 1998, o Programa Nacional de Educação na Reforma Agrária (PRONERA) e, em 2001, a aprovação das Diretrizes Operacionais para a Educação Básica nas Escolas do Campo. (FREITAS, 2007)

O PRONERA, criado durante o governo de Fernando Henrique Cardoso, tem como objetivo inicial a alfabetização de jovens e adultos no campo. Tal escolha teria se dado devido ao alto índice de analfabetismo na área rural. Apesar disso, ensino médio, técnico/profissionalizante, superior e até mesmo pós-graduação também fazem parte do programa. A populaçãoalvo do PRONERA são moradores de assentamentos criados pelo Instituto Nacional de Colonização e Reforma Agrária (INCRA) ou órgão estaduais que tenham parceria com o INCRA. No caso da alfabetização e do ensino fundamental de jovens e adultos, esse projeto visa atender também a moradores de acampamentos ainda não reconhecidos legalmente.

O PRONERA vincula-se ao INCRA e sua condução ocorre de forma tripartite: universidade, movimento social ${ }^{4}$ e o INCRA (representante do Estado) compõem a equipe que pensa ações e rege o programa. De acordo com Freitas (2007), tal composição gera alguns conflitos, pois ora movimento social e universidade não conseguem estabelecer uma síntese, ora movimento social e Estado divergem.

O MST tem um papel central na composição e na formulação do PRONERA. Freitas (2007) argumenta que:

Na preparação dos cursos do PRONERA, podemos afirmar, a princípio, que o MST mantém interfaces com todos os atores, uma vez que juntamente com as universidades são responsáveis pela elaboração dos projetos e negociação junto ao INCRA para sua aprovação. Mantêm interface também com os alunos que, com frequência, são militantes dos movimentos sociais do campo (FREITAS, 2007, p. 31)

Apesar do papel central do MST, não se pode desconsiderar a atuação da universidade na formulação de propostas para o programa e sua atuação no processo de ensino-aprendizagem. Afinal, de acordo com os direcionamentos do programa, os projetos desenvolvidos no PRONERA devem ter um professor da instituição de ensino que ficará responsável pela 
coordenação, formulação, implementação, pelo acompanhamento e controle técnico-operacional do projeto (Manual de Operações do PRONERA, 2004)

Os principais projetos atendidos pelo PRONERA são os de alfabetização e escolarização de jovens e adultos no ensino fundamental e capacitação e escolaridade de educadores (as) para o ensino fundamental em áreas da Reforma Agrária; formação continuada e escolaridade de professores(as) de áreas da Reforma Agrária (nível médio na modalidade normal ou em nível superior por meio das licenciaturas); formação profissional conjugada com a escolaridade em nível médio por meio de cursos de educação profissional de nível técnico ou superior (de âmbito estadual, regional ou nacional) em diferentes áreas do conhecimento voltados para a promoção do desenvolvimento sustentável no campo. Podem propor projetos para o PRONERA instituições públicas ou comunitárias sem fins lucrativos

Acerca dos princípios pedagógicos do programa, ele propõe-se a levar em conta a diversidade cultural, os processos de interação e transformação do campo, a gestão democrática e o avanço científico e tecnológico voltados para o desenvolvimento das áreas de Reforma Agrária. Tem como princípios norteadores da prática o diálogo, a práxis e a transdisciplinaridade.

Após mais de uma década de implementação do referido programa no Brasil, o INCRA buscou apresentar os resultados do projeto. Em uma pesquisa realizada em 2003, a partir de uma parceria entre o INCRA e a organização não governamental Ação Educativa ${ }^{5}$, foi feita uma avaliação sobre os resultados do programa. Aproximadamente $94 \%$ das ações educativas do PRONERA são voltadas para o EJA, sendo a maioria das ações voltadas paras as regiões Norte e Nordeste. De acordo com a pesquisa, entre 1999 e 2002, o programa teria sido responsável pela alfabetização de aproximadamente 110 mil alunos. Segundo dados divulgados no site do MST posteriores a tal pesquisa, de 2003 a 2008 cerca de 400 mil adultos foram escolarizados através do programa nas áreas de Reforma Agrária6.

Em um relatório da UNESCO, de 2008, que faz uma avaliação sobre os projetos educacionais brasileiros voltados para a alfabetização, são disponibilizados, também, alguns dados sobre os resultados do programa, no qual temos um aumento na quantidade de pessoas atendidas até 2006. Entretanto, apesar da numerosa quantidade de atingidos pelo PRONERA, o projeto, segundo a avaliação da ONG Ação Educativa publicada pela UNESCO, não serviu para modificar significativamente as condições de vida dessa população:

[...] o Pronera não impacta significativamente as condições de vida dos educandos devido à ausência e/ou insuficiência de políticas 
públicas outras de combate à pobreza, garantia de direitos e desenvolvimento rural, como o acesso ao crédito e à assistência técnica, melhoria das condições físicas de infra-estrutura (moradia, sistema viário, meios de transporte, iluminação, saneamento básico), segurança alimentar, saúde e educação escolar. Nessas condições, nem sempre a população assentada encontra suficiente motivação para engajar-se ou permanecer em processos educativos [...] Outra constatação comum a outros programas refere-se à dissociação entre a proposta metodológica de alfabetização de jovens e adultos e a prática docente dos educadores [...] (UNESCO, 2008, p.50, grifo nosso).

O PRONERA difere-se de boa parte dos programas voltadas para a educação no campo, pois origina-se da reivindicação dos trabalhadores e tem o movimento social, no caso o MST, como proponente e relativo condutor dos projetos elaborados. Entretanto, consideramos importante salientar que, como foi descrito por Freitas (2007), constantemente existem conflitos entre os principais atores (movimento social, universidade e Estado) envolvidos no projeto.

O conflito na condução do programa decorre principalmente por conta de projetos de sociedade distintos que cada um desses atores sociais almejam. O Estado é um organismo social empenhado em manter o capitalismo e sua exploração inerente, tratando a educação de maneira instrumentalista, enquanto, para setores da universidade e dos movimentos sociais, há a importância da ruptura com a lógica mercadológica da educação.

Esses conflitos podem tornar-se cada vez mais latentes também devido ao fato de, no manual de operações do PRONERA, estar previsto que as instituições habilitadas a propor projetos para o programa são instituições de ensino públicas ou comunitárias sem fins lucrativos. Já para ministrar cursos de ensino fundamental ou médio e educação profissional de nível técnico, e cursos de licenciatura ou bacharelado em Educação, cursos superiores em áreas de interesse dos movimentos sociais e sindicais de trabalhadores e trabalhadoras rurais reconhecidos pelo Ministério da Educação, somente serão aceitos os projetos cujos executores sejam universidades públicas ou comunitárias sem fins lucrativos ${ }^{7}$ (Manual de operações do PRONERA, 2004). $\mathrm{Na}$ atualização de 2012 do manual de operações, temos também como parceiras as instituições de ensino privadas, sem fins lucrativos.

Vemos então que o PRONERA mostra-se cada vez mais comprometido com a eficiência técnica e de resultados do que propriamente com a importante disputa ideológica no interior da escola. A luta ideológica acaba sendo abandonada na formulação teórica, quando aceitam-se instituições não comprometidas com a ideologia libertadora da educação. 
Ao ser abandonada a discussão ideológica nos documentos de condução da política, questionamo-nos também se a disputa ideológica não estaria restrita ao pequeno espaço e à pequena atuação do professor comprometido com o campesinato.

Além disso, não podemos deixar de enfatizar os perigos de se considerar instituições privadas e comunitárias sem fins lucrativos na proposição dos projetos. Apesar de constar no manual de operações que a aprovação dos projetos deve passar pelas três instâncias construtoras do PRONERA, como garantir que instituições sem fins lucrativos tais como o Instituto Souza $\mathrm{Cruz}^{8}$ tornem-se parceiros da Educação do Campo através do PRONERA? Legalmente isso é possível, o que resta é apenas a vontade, a força e o empenho do movimento dos sem-terra e da coordenação nacional para continuar impedindo isso.

\section{A UNESCO COMO PROTAGONISTA NAS IDEALIZAÇÕES DE PROJETO DE EDUCAÇÃO}

O movimento Educação do Campo foi instituído primeiramente como reivindicação dos movimentos sociais, em especial o MST, que sentem a necessidade de discutir a luta no plano ideológico desde cedo, na defesa da terra de trabalho, mas também devido à necessidade prática de ter escolas no campo para os filhos dos trabalhadores rurais, dos acampados e dos assentados, para que estes não tenham a necessidade de deslocar-se para a cidade, abandonando a luta e a terra de trabalho para escolarizar-se.

Neste sentido, lidamos na Educação do Campo com duas necessidades que são importantes, entretanto, não igualmente acatadas pelo Estado. De um lado, reivindica-se que a escola deixe de ser um dos locais de extrema importância do ponto de vista ideológico para a capitulação à lógica desigual do capital e à sua afirmação. $E$, de outro, temos uma antiga luta que se refere à universalização da educação pública, que faça com que a escola esteja próxima de todos aqueles que necessitam e almejam estudar, inclusive aqueles que vivem no campo.

O Estado, como um agente não neutro, mas sim comprometido com a reprodução do capital, lida com situações contraditórias a todo momento, as quais precisa resolver de uma forma em que o capital possa sempre avançar. Na luta de classes 9 , o Estado favorece a burguesia, entretanto, é, algumas vezes, forçado a "ceder" em determinados momentos para diminuir a tensão entre classes. Em certos momentos, inclusive, o Estado pode contradizer a "burguesia mais atrasada" e realizar certas reformas com o intuito de potencializar a reprodução capitalista (MASCARO, 2010) 
No que tange à educação, o que temos observado é, de certa forma, uma apropriação das teorias educacionais "mais avançadas" do ponto de vista pedagógico. Todavia, essa apropriação vem acompanhada também da ressignificação de tais teorias. Em relação à Educação do Campo, revelaram-se alguns fatos que demonstram um interesse do Estado brasileiro, influenciado pelos ditames de algumas organizações externas tais como o Banco Mundial e, mesmo que com menor poder, a UNESCO, em escolarizar o homem do campo. Fica claro, ao analisarmos os relatórios do Banco Mundial, que existe um interesse em desenvolver ("capitalisticamente") o campo brasileiro.

No final da década de 1990, tem-se uma efervescência dos movimentos sociais camponeses, mas também é o auge da subordinação do país aos organismos internacional (FMI, Banco Mundial). Nesse contexto, temse o marco de um diálogo entre governo, organismos multilaterais (UNESCO) e movimento social (MST). É nos anos 1997 que ocorre o primeiro ENERA, e as organizações que participam dele são CNBB, UNESCO, UNICEF, MST e UNB.

A participação da UNESCO e do UNICEF já nesse primeiro encontro, que marca o início da discussão sobre a necessidade de tornar a Educação do Campo uma política pública, merece destaque. Como vimos, em 1990, na Conferência de Jomtien, o Banco Mundial une-se à UNESCO no programa Educação para Todos, programa que reafirma a educação como ponto crucial de difusão do ideário neoliberal, difundindo a ideia de que, para um país crescer economicamente, necessita de capital humano. Questiona-se, assim, quais seriam o interesses dessas instituições, ambas ligadas à Organização das Nações Unidas (ONU), em participar de tal encontro para discutir uma educação de base anticapitalista, se o que defendem é, em si, uma educação voltada para a lógica do capital.

Essa participação da UNESCO nas discussões da Educação do Campo continua. Em 1998, as mesmas organizações se reúnem na I Conferência Nacional Por uma Educação do Campo. Essa conferência "batizou"a Educação do Campo como tal e ainda encabeçou a criação do PRONERA. Cabe lembrar que a presença da UNESCO não é novidade nos projetos educacionais para o campo. Em 1952, quando houve a Campanha Nacional de Educação Rural (projeto de educação para o campo ao qual o movimento Educação do Campo pretende se contrapor), um dos parceiros do Ministério da Educação era justamente a UNESCO.

Vemos, então, que a UNESCO se faz presente em projetos distintos de educação, tanto na antiga visão da escola rural como lócus do conhecimento mínimo para formação de mão de obra quanto no inovador projeto de 
educação para o campo encabeçado pelo MST e pelos demais movimentos do campo.

O PRONERA, segundo os autores estudados, surge como uma conquista dos movimentos camponeses. Nasce sob uma perspectiva distinta de parte das políticas educacionais, não é um programa de cima para baixo. Junto a ele, está o principal movimento social de luta pela terra, o MST. É construído através de uma parceria entre universidades, Ministério do Desenvolvimento Agrário e MST. Entretanto, com uma parceria cada vez mais próxima com a UNESCO. Mais uma vez, vemos programas distintos, com ideários pedagógicos e políticos distintos, com a colaboração e a proximidade da UNESCO.

O Ministério do Desenvolvimento Agrário (MDA), o Instituto Nacional de Colonização e Reforma Agrária (INCRA) e a Organização das Nações Unidas para a Educação, a Ciência e a Cultura (UNESCO) assinaram um protocolo de cooperação que prevê a produção e publicação de materiais didático-pedagógicos voltados para o meio rural, organização e realização de eventos e seminários de formação e capacitação de educadores, troca de experiências entre educadores da UNESCO e do Pronera, além da avaliação sistemática de projetos desenvolvidos no âmbito do Programa. O protocolo foi publicado no dia 13 de junho no Diário Oficial da União.

A coordenadora nacional do Programa Nacional de Educação na Reforma Agrária (Pronera), Mônica Molina, participou do encontro e destacou a importância do primeiro acordo de cooperação técnica assinado com a UNESCO em cinco anos de atividade do Programa. Para ela, o acordo de cooperação contribuirá para o desenvolvimento de uma pedagogia voltada às especificidades do universo agrário (MINISTÉRIO DO DESENVOLVIMENTO AGRÁRIO, 1999).

Para Agostini e Vendramini (2014), o PRONERA, apesar de ter surgido em meio à efervescência da luta, trazendo um caráter avançado, vem, ao longo dos anos, perdendo sua força, seu financiamento e sendo paulatinamente reduzido diante do Movimento Nacional pela Educação Básica do Campo, que tem uma influência ainda maior do UNICEF e da UNESCO, organizações que relativizam o caráter de classe da Educação do Campo e que modificam a centralidade da luta para questões focais, "não ideológicas".

Ao longo dos anos, as disputas voltam-se para o consenso, e a Educação do Campo passa a ter, cada vez mais, um caráter desenvolvimentista, genérico e não classista. Segundo Agostini e Vendramini (2014), esse caráter fica claro quando se aprovam as Diretrizes Operacionais para a Educação Básica nas Escolas do Campo (DOEBEC), Resolução CNE/CEB no 1, de abril de 
2002. De acordo com as pesquisadoras, as DOEBEC, apesar de constituírem uma legislação específica para a Educação do Campo, são diretrizes genéricas que tratam de princípios para uma educação no/do campo pensada a partir de sua realidade e suas potencialidades.

As próprias Diretrizes para a educação do campo respeitam e correspondem às diretrizes do $\mathrm{BM}$, como uma tática do Estado para atingir as metas de universalização da educação e demais questões pactuadas com estes organismos. Já para os movimentos sociais, avalia-se que foi necessária a produção de um consenso pela necessidade de acessarem a escola e a possibilidade de investimento em formação de professores (AGOSTINI; VENDRAMINI, 2014, p.308)

A Educação do Campo, como mais um dos elementos apropriados e ressignificados pelo Banco Mundial, é um retrocesso para a luta dos povos do campo. E, nesse processo, os trabalhadores se veem constantemente numa contradição, na qual, de um lado, há a luta pragmática e necessária pelo maior acesso à escola e pela erradicação do analfabetismo e, por outro, a luta política para a construção de uma nova educação que atenda universalmente aos trabalhadores.

\section{CONSIDERAÇÕES FINAIS}

Pensar em uma educação que o Estado hegemonize, em que o Estado imponha as regras, que domine não apenas financeiramente, mas politicamente, através de suas regras legais, que imponha desde a quantidade de dias letivos até as regras para a escolha dos professores que ali trabalharão, é pensar em uma escola que não educa para a emancipação.

Os trabalhadores entendem, de certa maneira, essa contradição, por isso propõem uma educação própria. Uma educação que realmente mostre aos educandos a realidade a partir de sua perspectiva. Sugerem, constroem o que seria essa escola diferente, aquela que traz a possibilidade de ruptura para o homem do campo. Assim, é sistematizada a Educação do Campo nesse contexto, tentando seguir esse direcionamento.

Entretanto, a Educação do Campo, quando sistematizada, conta, já de início, com os organismos multilaterais UNESCO e UNICEF, que já estiveram presentes na condução de diversos projetos educacionais, aos quais a Educação do Campo se propõe a ser um contraponto. Tais organizações, que mantêm estreita relação com o Banco Mundial, não se vinculam a projetos educacionais nos países periféricos sem propósito, apenas comprometidas com o fim do analfabetismo ou com qualquer outro pretexto meramente 
estatístico. Tais organizações contam com um projeto claro para a educação e uma concepção de educação que não tem como propósito a autonomia dos trabalhadores do campo, muito menos a destruição daquilo que os oprime, o latifúndio e o agronegócio.

Parece-nos claro o poder que o Banco Mundial exerce sobre o Estado brasileiro, e seus projetos para o campo são bem estruturados e sistematizados. O interesse do BIRD em educar o homem do campo traz consigo o desejo de difundir sua ideologia, bem como prover a mão de obra necessária para o capital.

Os trabalhadores precisam construir de maneira autônoma um projeto de educação, que não dependa dos organismos multilaterais nem de ações "comunitárias" de empresas. Tampouco deve-se permitir a ingerência do Estado nos projetos educacionais. A luta por uma educação emancipadora é árdua e não será admitida por aqueles que querem perpetuar-se no poder.

Artigo recebido em: 25/03/2017 Aprovado para publicação em: 16/05/2017

\section{STATE AND EDUCATION OF THE FIELD: THE INFLUENCE OF INTERNATIONAL ORGANIZATIONS IN THE PREPARATION OF PUBLIC EDUCATIONAL POLICIES FOR THE BRAZILIAN FIELD}

ABSTRACT: The beginning of the emergence of Field Education took place in 1997 at a meeting in Luziânia - GO organized primarily by the National Council of Bishops of Brazil (CNBB), the Workers Landless Movement (MST), the University of Brasilia and the International organizations: UNESCO and UNICEF. In our study we aim to analyze the contradictions of the institutionalization of Field Education. For this, we seek to reflect on the National Education Program in Agrarian Reform. We also aim to show the influence of the World Bank in educational projects and investigate its project for the field and education in the Brazilian countryside. For this, we use bibliographical and documentary research, analyzing World Bank reports, as well as data provided by the Ministry of Education.

KEYwords: World Bank. Field Education. Pronera. Unesco. 
ESTADO Y EDUCACIÓN DEL CAMPO: LA INFLUENCIA DE LOS ORGANISMOS INTERNACIONALES EN LA ELABORACIÓN DE POLÍTICAS PÚBLICAS EDUCACIONALES PARA EL CAMPO BRASILEÑO

RESUMEN: El surgimiento de la Educación do Campo tiene lugar en 1997, en una reunión en Luziânia -GO organizada principalmente por el Consejo Nacional de Obispos de Brasil (CNBB), Movimiento de los Trabajadores Sin Tierra (MST), la Universidad de Brasilia y las organizaciones internacionales: UNESCO y el UNICEF. En nuestro estudio se pretende analizar las contradicciones en la institucionalización de la Educación del Campo. Para ello, se reflexiona sobre el Programa Nacional de Educación en la Reforma Agraria. También tenemos como objetivo mostrar la influencia del Banco Mundial en proyectos educativos y la investigación de su proyecto para el campo y la educación en el campo brasileño. Para ello, se utiliza la investigación bibliográfica y documental, el análisis de los informes del Banco Mundial y los datos proporcionados por el ministerio de la educación.

Palabras clave: Banco Mundial. Educación Rural. Pronera. Unesco.

\section{NotAs}

$1<$ http://www.mst.org.br/Veja-o-manifesto-do-Forum-Nacional-de-Educacao-do-Campo>.

2 A Fundação Rockeffeller posteriormente uniu-se com a Fundação Ford e a USAID.

3 O PEA surgiu em 1997, durante o governo FHC, com a perspectiva de auxiliar o trabalho educativo com as classes multisseriadas, fundamentado nas orientações das "Diretrizes Operacionais para a Educação Básica nas Escolas do Campo" e, segundo Beserra, Martins e Souza (sem ano), sob influência e financiamento do Banco Mundial.

4 O MST é o movimento social mais significativo por conta de o PRONERA centrar-se em áreas de reforma agrária.

5 A ONG Ação Educativa é financiada tanto por agências internacionais (Fundação Ford, União Europeia, entre outros), como pelos "organismos multilaterais" (UNESCO, UNICEF) , por órgãos públicos nacionais (Conselho Nacional de Desenvolvimento Científico e Tecnológico (CNPq), Fundação Casa - Governo do Estado de São Paulo, Fundação de Amparo à Pesquisa do Estado de São Paulo (FAPESP), Fundo Municipal dos Direitos da Criança e Adolescentes (FUMCAD), Instituto Nacional de Pesquisa Educacionais Anísio Teixeira (INEP), Ministério da Cultura, Ministério da Educação, Prefeitura Municipal de São Paulo/Secretaria de Cultura, Secretaria de Educação de Bebedouro, Secretaria de Educação de Ipatinga/MG, Secretaria de Estado da Cultura de São Paulo) e por empresas nacionais (Caixa Econômica Federal, Fundação Itaú Social, Fundação Orsa, Fundação Roberto Marinho, Fundação Telefônica, Global Editora, Instituto C\&A, Instituto Embraer, Instituto Empreender, Instituto IBI, Instituto Paulo 
Montenegro - Ação Social do Grupo Ibope, Instituto Santander Banespa, Instituto Unibanco, Itaipu Binacional, Petrobrás S.A., Revista Carta Capital, SESC/São Paulo, SESC/DN, SESI/Bahia, SESI/DN).

$6<$ http://www.mst.org.br/book/export/html/107>.

7 Segundo a Lei $n^{\circ} 12.881$, de 12 de novembro de 2013, que dispõe sobre a definição, qualificação, prerrogativas e finalidades das Instituições Comunitárias de Educação Superior (ICES) e disciplina o Termo de Parceria e dá outras providências: Art. $1^{\circ}$ - As Instituições Comunitárias de Educação Superior são organizações da sociedade civil brasileira que possuem, cumulativamente, as seguintes características:I - estão constituídas na forma de associação ou fundação, com personalidade jurídica de direito privado, inclusive as instituídas pelo poder público;ll - patrimônio pertencente a entidades da sociedade civil e/ou poder público; III - sem fins lucrativos, assim entendidas as que observam, cumulativamente, os seguintes requisitos: a) não distribuem qualquer parcela de seu patrimônio ou de suas rendas, a qualquer título; b) aplicam integralmente no País os seus recursos na manutenção dos seus objetivos institucionais; c) mantêm escrituração de suas receitas e despesas em livros revestidos de formalidades capazes de assegurar sua exatidão.

8 O Instituto Souza Cruz vem se apropriando do discurso em defesa da Educação do Campo e lançando, através de sua ONG, ações para formação de jovens do campo com o objetivo de preparar mão de obra para o trabalho em suas unidades.

9 Utilizamos o termo "luta de classes", que muitas vezes é tido como ultrapassado, pois acreditamos primeiramente que devemos conceber a existência de duas classes distintas e que estas não têm o mesmo interesse, estando cotidianamente lutando para conquistar mais espaço. No caso da burguesia, a ampliação do seu domínio econômico, político e ideológico; no caso do proletariado, a libertação de suas amarras. Negar as classes sociais é negar a dominação e a luta pela libertação.

\section{REFERÊNCIAS}

BANCO MUNDIAL. Brazil, the management of agriculture, rural development and natural resources. Report n. 11783-BR, 1994.

BANCO MUNDIAL, Annual report. Washington DC, 1999.

BESERRA, S. B.; MARTINS, A. C. L. ; SOUZA, O. N. B. de. Políticas de educação básica e de formação e gestão escolar: a implementação do Programa Escola Ativa no estado do Pará - Um estudo dos processos instituídos a partir de 2008 na educação do campo paraense. Disponível em: <http://www.anpae.org.br/simposio26/1comunicacoes/ SoelmaBeloBeserra-ComunicacaoOral-int.pdf>.

D’AGOSTINI, A.; VENDRAMINI, C. R. Educação do campo ou educação da classe trabaIhadora? A perspectiva do empresariado, do Estado e dos movimentos sociais organizados. Revista Reflexão e Ação, Santa Cruz do Sul, v. 22, n. 2, p. 299-322, jul./dez.2014 
FREITAS, H. C. de A. A construção da rede sócio-técnica de educação de assentados da reforma agrária: o PRONERA. 2007. 225 f. Tese (Doutorado) - Programa de Pós-Graduação em Sociologia Política da UFSC, Florianópolis, 2007.

JÚNIOR, W. P. da M.; MAUÉS, O. C. O Banco Mundial e as políticas educacionais brasileiras. Educação \& Realidade, Porto Alegre, v. 39, n. 4, p. 1137-1152, out./dez. 2014.

LEHER, R. Um novo senhor da educação? A política educacional do Banco Mundial para a periferia do capitalismo. Outubro, São Paulo, v. 1, n. 3, p. 19-30, 1999.

MASCARO, A. L. Estado e forma política. São Paulo: Boitempo Editorial, 2010.

MINISTÉRIO DO DESENVOLVIMENTO AGRÁRIO, 1999. Disponível em: <http:// www.mda.gov.br/sitemda/noticias/mda-e-unesco-discutem-parceria-para-educa\%C3\%A7\%C3\%A3o-no-meio-rural\#sthash.MgS4c83r.dpuf>. Acesso em: jun, 2015.

PEREIRA, J. M. L. O Banco Mundial como ator político, intelectual e financeiro 1944-2008. Rio de Janeiro: Editora Civilização Brasileira, 2010.

PRONERA. Manual de Operações do Pronera. 2004. Disponível em: <http://www.incra. gov.br/sites/default/files/programa_nac_educacao_reforma_agraria.pdf >.

RIBEIRO, M. Movimento camponês, trabalho e educação, liberdade, autonomia, emancipação: princípios/fins da formação humana. São Paulo: Editora Expressão Popular, 2010. RIBEIRO, M. Educação do Campo e escola ativa: contradições na política educacional no Brasil. Educação em Revista, Marília, v.12, n.2, p.23-40, jul./dez. 2011.

RABELO, J.; JIMENEZ, S. Educação para todos e a reprodução do capital. Revista Trabalho Necessário, ano 7, n. 9, 2009.

SANTOS, A. R. dos. Ocupar, resistir e produzir, também na educação! O MST e a burocracia estatal: negação e consenso. Jundiaí (SP) Paco Editorial, 2013.

SAVIANI, D. Pedagogia histórico-crítica: primeiras aproximações. 8. ed. Campinas: Autores Associados, 2003

UNESCO. Alfabetização de jovens e adultos no Brasil: lições da prática. Brasília, 2008. $212 \mathrm{p}$.

. Declaração Mundial sobre Educação para Todos: satisfação das necessidades básicas de aprendizagem. Jomtiem,1990, 1998.

WORLD BANK Support for Developing Countries on International Trade Issues, Development Committee, Washington DC, September. 
SOARES, S. B.

SÁvia Bona SOARES: Bacharela e Licenciada em Geografia pela Universidade de Brasília $\left(U_{n} B\right)$, mestra em Geografia pela UnB e professora de Geografia da Secretaria de Educação do Distrito Federal (SEE-DF).

E-mail:saviabona@gmail.com 